\title{
Urinary Tract Infection Treatment Pattern of Elderly Patients in a Tertiary Hospital Setup in South India: A Prospective Study
}

\author{
Ramanath Katta Venkatesh',2, Mukhyaprana M Prabhu³, Krishnadas Nandakumar', K Sreedhara R Pai ${ }^{*}$ \\ 'Department of Pharmacology, Manipal College of Pharmaceutical Sciences, Manipal University, Manipal-576104, Karnataka, INDIA. \\ 2Department of Pharmacy Practice, Sri Adichunchanagiri College of Pharmacy, BG Nagar, Nagamangala, Mandya District, Karnataka, INDIA. \\ 3Department of Medicine, Kasturba Medical College, Manipal University Manipal-576104, Karnataka, INDIA.
}

\begin{abstract}
Introduction: Urinary tract infections (UTIS) are more common in geriatrics due to physiological alterations/pathological conditions. The main objective of this study was to analyze the incidence, causative organisms, types of antibiotics used, drug interactions, the antibiotic cost, and its outcome. Method: This is across-sectional study conducted in selected medicine units over a period of 18 months. The enrolled patient's therapy pattern spotted from the admission to discharge. The mandatory patients provided with pharmaceutical care services. Results: Among 475 observed cases, 106 patients had UTIs $(22.31 \%)$. The mean number of drug were $7.42 \pm$ 2.31 per prescription. Out of 106 prescriptions, 63 prescriptions had drug interactions. The drug interactions degree varied from mild (12.63\%), moderate $(60.3 \%)$ and severe $(26.58 \%)$ remained managed by spacing intervals, alternate drug use, and close monitoring techniques. Strangely, all comorbid UTI patient outcomes showed improvement. The antibiotic cost of the management ranged from $\$ 0.21-160.8$ with a median of $\$ 26.30$ and the common organisms were E. coli (48\%), Enterococcus $(16 \%)$. The average length of patient hospital stay was $11.65 \pm 8.94$ days. Conclusion: This study showed that about one-fourth patients have UTIs and half of
\end{abstract}

them were affected by E. coli. Hence, this study proposes the paucity and its implication of pharmaceutical care service research studies, on healthhygiene, proper use of antibiotics \& its cost minimization; untoward interactions cost prevention, for better outcome in India.

Key words: Urinary tract infection (UTI), Drug interaction (DI), Geriatrics, Hypertension( HTN), Discharge against medical advice (DAMA), Tricyclic antidepressants (TCA), HCT: Hydrocholrothiazide.

\section{Correspondence :}

Dr. K. Sreedhara R. Pai,

Department of Pharmacology, Manipal College of Pharmaceutical Sciences,

Manipal University, Manipal-576104, Karnataka, INDIA.

Phone no: +91-820-2922482; Fax no: +91-820-2571998

Email: ksr.pa@manipal.edu, kvr1075@gmail.com

DOI: 10.5530/jyp.2016.2.9

\section{INTRODUCTION}

Urinary tract infection (UTI) is one of the most prevailing causes of infectious diseases (shared by bacteria) among the geriatric population in both genders. ${ }^{1}$ Due to their anatomy and reproductive physiology, women are more susceptible. ${ }^{2,3}$ However, between females and males, the ratio varies from geriatrics (50:1) to younger (2:1) population. ${ }^{4}$ Diagnosis and treatment of UTI in elderly varies when compare to younger patients and is quiet difficult due to the non-specific/absence of symptoms and lack of clear clinical history. ${ }^{5}$ This lead toits under-diagnosisandlack of treatment. ${ }^{6}$

Previous studies showed that UTI is often erroneously diagnosed, with around $40 \%$ of hospitalized elderly admissions due to non-specific symptoms. Even studies reported that the UTI was caused due to urinary incontinence, previous history, urogenital surgery and diabetes mellitus in specific patient populations. ${ }^{3,4}$

Bacteria is the most common causative agent in humans. Even though sometimes viruses and fungi can also be observed, hence this should not be ignored. Common infecting organisms are Escherichia coli (80\% to $85 \%$ ) and Staphylococcus saprophyticus (10\% to $15 \%$ ), while Klebsiella pneumonia, Pseudomonas and Proteus species account for the rest of the infections.

Among the two urinary tract infections, Nosocomial UTIs is major, caused by Escherichia coli, Pseudomonas aeruginosa and Proteus sp, whereas community acquired is caused by Escherichia coli, Klebsiella pneumonia, Proteus mirabilis and Staphylococcus saprophyticus. ${ }^{8}$

Previous studies showed that increased mortality associated with bacterial infections, in older UTI patients was more and extensive need for prevention with early diagnosis of UTI is vital to reduce morbidity and mortality. ${ }^{9}$

Antibiotics play a vital role in the treating of bacterial UTIs and in the majority of cases the initial empirical treatment is with broad spectrum antibiotics. ${ }^{10}$ Unfortunately, this trend of antibiotic usage leads to antibiotic resistance, the emergence of multi-drug resistant (MDR) strains (Clostridium difficile infection) and adverse drug reactions (ADRs). ${ }^{11}$ At present, antibiotic resistance (MDR strains) is a global concern which greatly affects the cost of treatment, hospitalization period, morbidity and mortality of patients in healthcare. ${ }^{12}$ Hence, the use of broad spectrum antibiotics should be minimized and a more targeted approach to therapy can be devised with narrow spectrum based antibiotic susceptibility patterns of isolated organisms from patients. The antibiotic policy of respective hospitals should be in place to guide the doctors in selecting appropriate antibiotics. Hence, this study conducted in hospitalized elderly patients with the following objectives, namely to understand the treatment pattern, to measure the incidence of UTI, causative organisms, usage of antibiotics, antibiotic susceptibility pattern, drug interactions, the direct cost burden of antibiotic treatment, hospitalization period and its clinical outcome.

\section{METHODOLOGY}

A prospective observational study was conducted in selected General medicine units of Kasturba Hospital, Manipal, Karnataka over a period of 18 months (July 2012 to January 2014) after getting Institutional ethical clearance (IEC: 191/2012). The patients were enrolled as per the listed criteria (Inclusion criteria: 1. Patients of either sex of 60 years and above. 2. A patient, willing to give informed consent form. 
Exclusion criteria: Comatose patients, $>2$ months, Hospital stay, $\geq 5$ comorbid disease), after getting their informed consent. Patient case records werestudied,reviewedand datacollectedondemographics(age,sex),medical history, diagnosis, co-morbidities, microbiological reports (antibiotic susceptibility), drug treatment chart, and duration of hospitalization and clinical outcome of the patients with well-designed data collection/case report form (CRF). Prescribed drugs were checked for drug interactions by using sources of drug information (Micromedex 2.0, Medscape) and if necessary informed to the clinician. The patients and caretaker were provided with verbal patient counseling on proper use of antibiotic and patient outcomes were assessed based on their laboratory parameter and their satisfaction. The total costs incurred by use of antibiotics in these patients were calculated. A descriptive statistical analysis carried out by using statistical package social sciences (SPSS version 20.0).

\section{RESULTS}

Among 475 enrolled subjects, 106 patients had urinary tract infection (22.31\%) of which 56males (53\%) constituted the majority. Patients with age group between 60-65 years were $52 \%$, out of which males were dominant, followed by 66-70 years of age (Table 1 ).

Type 2 diabetes mellitus and hypertension are the most common co-morbidities, either alone or combined. The major diagnosis revealed type II diabetes mellitus UTI $(43 ; 40.6 \%)$ followed by hypertension UTI $(38 ; 35.8 \%)$ and type II diabetes mellitus with hypertension UTI (25; $23.6 \%)$. Interestingly, no UTI alone cases were observed in our study population.

Out of 106 patients, the culture sensitivity test was performed in 83 patients for various biological specimens (sputum, broncho-alveolar lavage fluid, blood, pleural fluid, wound swab and endo-tracheal aspirate). Of these, 36 patient specimens were sterile and the rest 47 (44.3\%) showed growth of different organisms, wherein 50 organisms are isolated. Out of 50 organisms, 47 organisms were isolated from urine samples (bacteria), followed by one isolate from blood, endotracheal aspirate and sputum (fungi: Candida species) each. The majority (44;88\%) were mono isolates and the rest were multiple (two pathogens) isolates.

Gram negative organisms were more frequently isolated than gram positive (66\% vs. $28 \%)$. Escherichia coli $(48 \%)>$ Klebsiella (10\%)and Enterococcus species (16\%) > Methicillin resistant Staphylococcus aureus (MRSA)were the most prevalent gram negative and gram positive organisms, respectively. (Table 2).

Sensitivity studies of $E$. colirevealed Amikacin, Netilmicin and Imipenem were $100 \%$ sensitive followed by Cefoperazone-Sulbactam (95\%) and Piperacillin-Tazobactam (77.2\%). Aztreonam, Ticarcillin-Clavulanic acid, Cefazolin or Cefodroxil and Ciprofloxacin or Levofloxacin were completely resistant.

Antibiogram of the remaining isolates are not taken into consideration as the number of organisms isolated was very less.

Table 1: Distribution of patients based on age

\begin{tabular}{ccccc}
\hline Age group (years) & Females & $\%$ & Males & $\%$ \\
\hline $60-65$ & 23 & 46 & 32 & 57.1 \\
$66-70$ & 13 & 26 & 12 & 21.42 \\
$71-75$ & 06 & 12 & 8 & 14.2 \\
$76-80$ & 06 & 12 & 3 & 5.35 \\
$81-85$ & 01 & 2 & 0 & 0 \\
$86-90$ & 01 & 2 & 0 & 0 \\
$91-95$ & 00 & 00 & 1 & 1.78 \\
Total & 50 & 100 & 56 & 100 \\
\hline
\end{tabular}

Table 2: Most prevalent organisms in Urinary tract infections

\begin{tabular}{cccc} 
Type of microbe & Organism & $\begin{array}{c}\text { Number of } \\
\text { isolates }\end{array}$ & $\begin{array}{c}\text { Percentage } \\
\text { of isolates }\end{array}$ \\
\hline & E coli & 24 & 48 \\
Gram Negative & Klebisiella pneumonia & 5 & 10 \\
bacteria (66\%) & $\begin{array}{c}\text { Sseudomonas aeruginosa } \\
\end{array}$ & 2 & 4 \\
& Serratiasps & 1 & 2 \\
Citrobacterkoseri & 1 & 2 \\
Gram Possitive & Enterococcus sps & 8 & 16 \\
bacteria (28\%) & MRSA & 3 & 6 \\
& Staphylococcus aureus & 2 & 4 \\
Fungus (6\%) & MSSA & 1 & 2 \\
& Candida sps & 3 & 6 \\
& Total & $\mathbf{5 0}$ & $\mathbf{1 0 0}$ \\
\hline
\end{tabular}

Table 3: Sensitivity pattern of the antibiotics used in UTI patients

\begin{tabular}{ccccc}
\hline Antibiotic & Sensitive & $(\%)$ & Resistance & $(\%)$ \\
\hline Netilmicin & 24 & 100 & 0 & 0 \\
Amikacin & 24 & 100 & 0 & 0 \\
Imipenem & 22 & 100 & 0 & 0 \\
Cefoperazone-Sulbactam & 21 & 95.5 & 1 & 4.5 \\
Piperacillin-Tazobactam & 17 & 77.2 & 5 & 22.8 \\
Gentamicin & 14 & 58.3 & 10 & 41.7 \\
Cotrimoxazole & 6 & 25 & 18 & 75 \\
Norfloxacin & 3 & 15 & 17 & 85 \\
Amoxicillin-Clavulanic acid & 2 & 8.3 & 22 & 91.7 \\
Ampicillin/Amoxicillin & 2 & 8.3 & 22 & 91.7 \\
Cefotaxime/Ceftriaxone & 2 & 8.3 & 22 & 91.7 \\
Cefuroxime & 2 & 8.3 & 22 & 91.7 \\
Cefpirome, Cefepime & 1 & 4.5 & 21 & 95.5 \\
Aztreonam & 0 & 0 & 22 & 100 \\
Ticarcillin-Clavulanic acid & 0 & 0 & 14 & 100 \\
Cefazolin/Cefodroxil & 0 & 0 & 4 & 100 \\
Ciprofloxacin/Levofloxacin & 0 & 0 & 4 & 100 \\
\hline
\end{tabular}

Out of 106 UTI cases admitted to the general medicine unit, 105 (99\%) are prescribed with antibiotics. Amongst these antibiotic prescriptions, 55 (52.4\%) prescriptions had a single antibiotic followed by 2, 3 and 4 antibiotic containing [i.e., 30 (28.6\%), 19 (18.1\%) and 1 (1\%)] prescriptions, but they were not necessarily administered simultaneously. Most of the patients received antibiotics parenterally (41.5\%), followed by both parenteral and oral route $(40.6 \%)$ and oral route alone $(17 \%)$. The total number of antibiotics prescribed among the 106 patients was 176. The average number of antibiotics per prescription was $1.68 \pm 0.8$ (mean $\pm \mathrm{SD}$ ). The mean, median and interquartile range (IQR) of antibiotic cost per the management UTIs was $2249.14 \pm 2181.94$, \$ 26.38 (Rs. 1729) \&: \$ 40.10 (Rs. 2628) (Table 3, 4, 5).

Cephalosporin combination with $\beta$-lactamase inhibitors was the most prescribed class of antibiotic 38 (36\%) followed by penicillin in combination with $\beta$-lactamase inhibitors, because of good spectrum of activity and suggestive culture sensitivity. The resistant organism was treated with drugs like Linezolid and Piperacillin/Tazobactam. Even we can observe 
Table 4: Antibiotics usage pattern in UTI treatment

\begin{tabular}{ccc}
\hline Number of antibiotics & Frequency of use & $\%$ \\
\hline 0 & 1 & 100 \\
1 & 55 & 52.4 \\
2 & 30 & 28.6 \\
3 & 19 & 18.1 \\
4 & 1 & 1.0 \\
Total & $\mathbf{1 0 5}$ & $\mathbf{1 0 0 . 0}$ \\
\hline
\end{tabular}

Table 5: Mode of administration of antibiotics in UTI treatment

\begin{tabular}{ccc}
\hline Mode of antibiotic administration & Frequency of use & $\%$ \\
\hline None & 1 & .9 \\
Injection & 44 & 41.5 \\
Oral & 18 & 17.0 \\
Injection+ Oral & 43 & 40.6 \\
Total & $\mathbf{1 0 6}$ & $\mathbf{1 0 0 . 0}$ \\
\hline
\end{tabular}

Table 6: Class of antibiotics used in treatment of Urinary tract infection

\begin{tabular}{cc}
\hline Antibiotics usage pattern & $\begin{array}{c}\text { Number of } \\
\text { prescriptions (\%) }\end{array}$ \\
\hline Cefaperazone+Sulbactum & $38(35.84)$ \\
Amoxycillin+Clavalunic acid & $17(16.03)$ \\
Nitrofurantoin & $11(10.3)$ \\
Linezolid & $8(7.54)$ \\
Cotrimoxazole & $7(6.6)$ \\
Ciprofloxacin & $6(5.6)$ \\
Piperacillin+Tazobactum & $5(4.7)$ \\
Amikacin & $3(2.83)$ \\
Others & $11(10.3)$ \\
Total & 106 \\
\hline
\end{tabular}

\begin{tabular}{ccc}
\multicolumn{3}{c}{ Table 7: Classification of Drug interactions based on severity } \\
\hline DDI Severity & Yes(\%) & No(\%) \\
\hline Mild & $8(12.63)$ & $55(87.4)$ \\
Moderate & $38(60.31)$ & $25(39.68)$ \\
severe & $17(26.98)$ & $46(73.1)$ \\
Total & $63(100)$ & \\
\hline
\end{tabular}

commonly used drugs like Co-trimoxazole, Nitrofurantoin and Ciprofloxacin because of economic consideration and severity of the disease (Table 6).

Of all the UTI cases, 63 (60\%) patient treatment charts showed drugdrug interactions. Of these, 38 are moderate, followed by 17 severe and 8 mild (Iron with Ciprofloxacin, Omeprazole and Vitamin with Omeprazole, Nitrofurantoin). The entire drug-drug interactions are informed to respective physicians with evidence/literature. Among these severe drugdrug interactions were considered significant and an alternative therapy was prescribed (eg: Alprazolam with codeine sulphate) and sometime close monitoring were observed (e.g. aspirin/naproxen with duloxetine) If not possible, then the dosing interval was changed (e.g. amitriptyline with duloxetine and linezolid combination)(Table 7, 8, 9).

The outcome of the most $(68 ; 64.1 \%)$ of the patients showed were improved, followed by stable $(26 ; 24.5 \%)$, died $(5 ; 4.7 \%)$ and worsened
(1; $0.95 \%)$ during hospitalization. A minor fraction (8.5\%) of patients was discharged against medical advice and discharge on request due to Financial constrains (Figure 1).

The mean age, average days of hospitalization and the mean number of drugs per prescription of the study population was $67.8 \pm 6.64,11.65 \pm$ 8.94 and $7.41 \pm 2.31$, respectively.

\section{DISCUSSION}

Urinary tract infections are one of the most common infections in geriatrics due to physiological variations. If chronic diseases like diabetes, HTN are concomitantly present, the chances of an UTI are higher and can even sometimes lead to mortality. ${ }^{6}$ The research on treatment pattern/drugs used by the pharmacist becomes complimentary for physicians to achieve rational drug usage and provide a better outcome. Our study showed that the UTI was more prevalent among males (53\%) than females (47\%) which is similar to the study conducted by Faryabi et al. (males vs. females: $54.2 \%$ vs. $45.8 \%),{ }^{14}$ Mahesh et al. (males vs. females: $62.4 \%$ vs. $37.6 \%)^{15}$ and Arul Prakasam et al. ${ }^{16}$ where UTI was predominantly observed in male $(85.7 \%)$. In contrast, the study conducted by Prakash and Saxena (males v.s females: $35.14 \%$ vs. $73.57 \%$ ) showed the opposite. ${ }^{17}$ UTI was most commonly witnessed in both the genders in the age group of 60-65 years, whereas in the study carried out by Dinesh and his team, ${ }^{13}$ UTI was more common in females of age group 31-45 years. ${ }^{17,18}$ This difference might be because our study was conducted in geriatric populations whose comorbidities such as diabetes mellitus and increasing risk of age related prostate disorders increased its incidence.

In our study population, out of all UTI cases, $64.1 \%$ of cases have a history of diabetes mellitus whereas the study conducted by Pargavi et al. in diabetic patients showed an incidence of $37 \%$ of UTI, ${ }^{18}$ Marques et al. study ${ }^{19}$ showed 23.52\% had DM-UTI and in Mahesh et al. study, ${ }^{15} 42.6 \%$ of the study population has a history of diabetes mellitus. This shows that diabetes mellitus is one of the major risk factors for the incidence of UTI. Fu et al. study also showed $20.2 \%$ elderly DM patients had UTI in their DM management follow ups. ${ }^{20}$

The average length of hospitalization was11.65 \pm 8.94 days, which is closer to Faryabi et al. (10.72 \pm 5.2 days) study. ${ }^{14}$ Most of the patients $(52.4 \%)$ was prescribed with single antibiotic, whereas in a study conducted by Faryabi et al. dual drug (antimicrobial agent) regimens were high (38\%) but more or less same for a single drug regimen $(31.3 \%) .{ }^{14}$

The most commonly prescribed antibiotics were Cephalosporin (36\%) which is similar to studies conducted by Faryabi et al. and Ramanath and Shafiya. ${ }^{21}$ Next, extended spectrum penicillin in combination with $\beta$-lactamase inhibitors was routinely prescribed identical to Faryabi et al. study. ${ }^{14}$ Aminoglycosides were the least prescribed antibiotics, even though highly sensitive to commonly isolate organisms in UTI patients. This is due to the renal toxicity of drugs and age related renal impairment among the patients which is considered to be significant.

Gram negative organisms such as E. coli $(24 ; 48 \%)$ were the frequent cause of UTI which was in lines with the data available worldwide and confirmed by Faryabi et al., ${ }^{14}$ Arslan et al. ${ }^{22}$ Peterson et al. ${ }^{23}$ and Marques et al. ${ }^{19}$ studies (75.6\% E. coli). Among gram positive organisms which accounts for $28 \%$ of isolates, it chiefly constituted Enterococcus sps (8) and Staphylococcus sps (MRSA; 3, Staphylococcus aureus; 2 and MSSA; 1). In our study, E. coli was completely sensitive to amikacin, netilmicin, imipenam followed by cefoperazone sulbactam (95.5\%) which is similar to the study conducted by Faryabi et al. ${ }^{14} \mathrm{E}$. coli is highly resistant to fluoroquinolones (levofloxacin/ciprofloxacin; $100 \%$ and norfloxacin; $85 \%)$ which area contrast to study conducted by Shalini et al. which showed, levofloxacin (75\%), ciprofloxacin (73.9\%) and norfloxacin 
Table 8: List of moderate Interactions

\begin{tabular}{|c|c|}
\hline Drug+Drug & Effect \\
\hline Insulin Regular+Linizolid & $\uparrow$ the Hypoglycemia condition \\
\hline Insulin + Norfloxacin & $\uparrow$ risk of hypoglycemia or hyperglycemia \\
\hline Asprin + Furosemide & $\downarrow$ diuretic and anti-hypertension \\
\hline Nefidipine+Metorprolol & $\uparrow$ Hypotension, Bradycardia \\
\hline Atorvastatin $+\mathrm{Niacin}$ & $\uparrow$ the Risk of myopathy \\
\hline Glipizide+Metformin+Ciproflaxacin & $\uparrow$ Hypo or hyperglycemia \\
\hline Glimiperide+Propronalol & $\uparrow$ Hypo/hyper or HTN \\
\hline Pantorpazole+Propranalol & $\uparrow$ Prorporonalol toxicity \\
\hline Metaprolol+Tamsulosin & Exaggerate Hypotensive alpha blocker. \\
\hline Metprolol+Metformin & $\uparrow$ Hypo or Hyperglycemia or HTN \\
\hline Amlodipine+Clopidegraol & $\downarrow$ antiplatelet effect \\
\hline Asprin + Clopidegrol & $\uparrow$ the risk of Bleed \\
\hline Ramipril+Amiloride/Spironolactone & Hyperkalemia \\
\hline Asprin+Amiloride/Amlodipine/Diclofenac & GI haemorrahge,Antagonist effect of Hypotensive effect \\
\hline Clopidegrol+Omepragole & $\downarrow$ clopidegrol effect \\
\hline Ferrous Feumarate+Pantoprazole & $\downarrow$ Iron Bioavailability \\
\hline Asprin+Calcium carbonate /Vitamin D.- & $\downarrow$ Salicylate effectiveness \\
\hline Asprin+Insulin lispro/Glimepiride & $\uparrow$ Risk of hypoglycemia \\
\hline Ferrous fumarate/Folic acid+Pantoprazole- & $\downarrow$ Iron bioavailability \\
\hline Carvidalol+Isophane Insulin/Metformin & Hypoglycemic or Hyperglycemia \\
\hline Carvedilol+Tamsulosin & Exaggerate hypotensive \\
\hline Metformin/Glimiperide+Levothyroxine- & $\downarrow$ antidiabetic effect \\
\hline Levothyroxine+Pantoprazole- & $\downarrow$ TSH level \\
\hline Amlodipine+Asprin & Hypotensive effect, GI hemorrhage \\
\hline Asprin + Furosemide & $\downarrow$ Diuretic effect and antihypertensive effect \\
\hline Glimiiperide+TriMethorpim+SulphaMethaxazole & Excessive hypoglycemia \\
\hline Calcium carbonate + Hydro.chlorthiazide/Telmisartan & $\uparrow$ risk of hypercalcemia \\
\hline Prednisalone+HydroChloroThiazide/Telmisartan & Hypokalemia \\
\hline Clonidine+Insulin Glargine & Hypoglycemia or Hyperglycemia \\
\hline Atorvastatin + Clopidegrol & high on-treatment platelet reactivity \\
\hline Atorvastain + Digoxin & $\uparrow$ plasma concs of digoxin \\
\hline Digoxin+Omeprazole,furosemide & digoxin toxicity \\
\hline Levothyroxine+MetforminHcl & $\downarrow$ effectiveness of the antidiabetic agent \\
\hline Ciprofloxacin + ferrous fumarate- & $\downarrow$ ciprofloxacin effectiveness, \\
\hline Cefaperazone/warfarin+pantaprazole & increased risk of bleeding \\
\hline diclofenac+ramipril & $\downarrow$ Ramipril effectiveness \\
\hline diclofenac+Ramipril+glimiperide & $\uparrow$ hypoglycemia \\
\hline Furosemide+ramipril- & Postural hypotension (first dose). \\
\hline Omeprazole+Propranalol & $\uparrow$ propranolol exposure \\
\hline Calcium carbonate/vit D-propranalol HCL & $\downarrow$ propranolol bioavailability \\
\hline Calcitrol+Magnisum HCL & Hypomagnesemia. \\
\hline Clonazepam+theophylline & $\downarrow$ benzodiazepine effectiveness \\
\hline Iron + zinc & $\downarrow$ gastrointestinal absorption of iron and/ or zinc \\
\hline Asprin+Metaprolol/telmisartan & $\downarrow$ the antihypertensive effect \\
\hline Asprin + Prednisalone & $\uparrow$ the risk of GI bleed \\
\hline
\end{tabular}


Table 9: List of severe Interactions

\begin{tabular}{|c|c|}
\hline Drug+drug & Effect \\
\hline Atorva statin + Fenofibrate & $\uparrow$ Myopathy/Rhabdomyolysis \\
\hline Clonidine+Diltizeam & $\uparrow$ Sinus Bradycardia \\
\hline furosemide + Metalazone & $\uparrow$ electrolyte \& fluid imbalances \\
\hline Azithromycin+Salmetraol & $\uparrow \mathrm{QT}$ prolongation \\
\hline Aspirin--Prednisolone & $\begin{array}{c}\uparrow \text { risk of gastrointestinal ulceration and Sub therapeutic } \\
\text { aspirin serum concentrations }\end{array}$ \\
\hline Amitryptlin/TCA+Levothyroxine- & $\begin{array}{l}\uparrow \text { therapeutic and toxic effects of both levothyroxine and } \\
\text { tricyclic antidepressant }\end{array}$ \\
\hline $\begin{array}{l}\text { Amitryptilin/Duoloxetine/Linezolid+acitamenophenon/ } \\
\text { Tramadaol- }\end{array}$ & $\uparrow$ of seizures, serotonin syndrome \& $\uparrow$ Tramdolconc \\
\hline Insulin human $(\mathrm{R})+\mathrm{HCT} /$ losartan & $\uparrow$ hypoglycemia \\
\hline Alprazolam + Codeine sulfate & $\uparrow$ respiratory depression \\
\hline Aspirin + Hydrochlorothiazide/Losartan & $\downarrow$ antihypertensive effects and $\uparrow$ renal impairment \\
\hline Digoxin + Spiranolactone & $\uparrow$ digoxin exposure \\
\hline Asprin+Duoloxetin & Increased risk of bleeding \\
\hline Duoloxetin+Napraxean & $\uparrow$ risk of bleeding \\
\hline Ciprofloxacin + Hydralazine $\mathrm{HCl}$ & $\uparrow$ risk for Bleeding \\
\hline
\end{tabular}

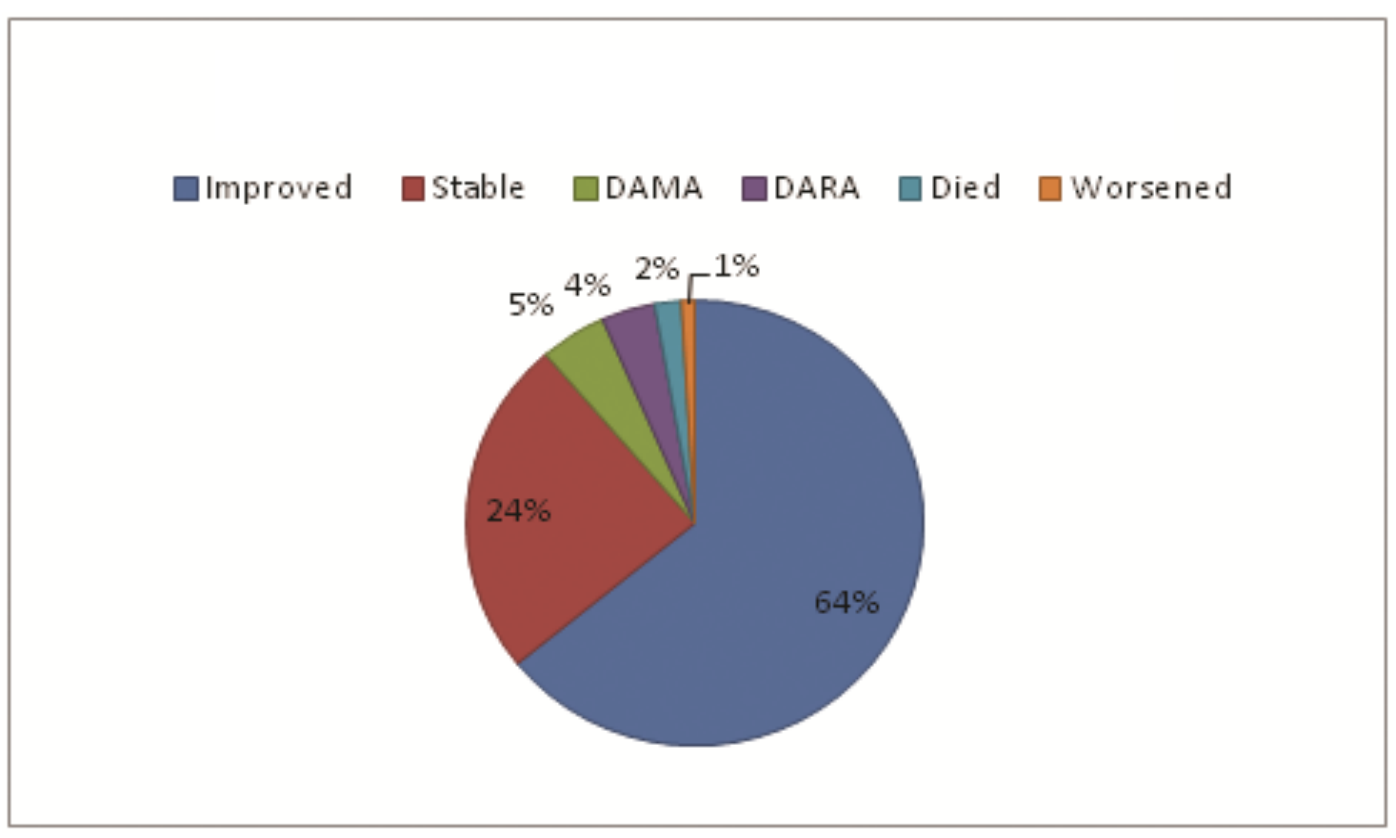

Figure 1: Clinical outcomes of UTI treatment patients

(69.6\%) as sensitive. ${ }^{24}$ Antibiotic susceptibility pattern of other organisms isolated was not considered as significant in view of less numbers of isolation.

\section{CONCLUSION}

This study clearly suggests that pharmaceutical care services are vibrant in elderly for the prevention and/or minimization of drug interactions, proper usage and rational promotion of drugs even though it was conducted only in selected medicine departments of the hospital. This study also suggests that educational interventions regarding strict control and monitoring of the chronic disease condition help in avoiding recurrence of UTIs. In addition, home medication review research studies can prove to be vital to elderly patients having financial constraints.

\section{ACKNOWLEDGMENT}

We are thankful to AICTE-QIP scheme for supporting this research. The authors also thank Manipal University for facilitating this research work.

\section{CONFLICT OF INTEREST}

The author declare no conflict of interest. 


\section{ABOUT AUTHORS}

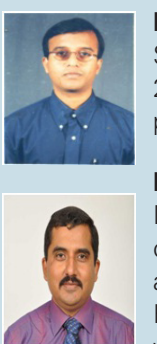

K. V. Ramanath: Is Quality improvement Research scholar (doctoral student) from Manipal University and also staff (Associate Professor) in SAC College of pharmacy in the department of Pharmacy practice. He graduated in Pharmacy in 1997, Masters in Pharmacy practice in the year 2000 and also MBA (HRM) distance education from AnnamalaiUniversity in the year 2006. His doctoral research mainly focuses on geriatric pharmaceutical care concepts (Patient counseling, Drug use patterns, Minimization of drug related issues) and Pharamco-economic studies.

Dr Mukhyaprana M Prabhu: Working as Professor and unit head in the Department of general medicine Kasturba Medical college and hospital, Manipal. He is also Joint secretary MAHE Research Committee (MRC).Member Pharmaco vigilance committee KMC Manipal, Member MCI compliance committee, faculty Coordinator for Manipal University Maastricht student exchange programme. He also served in various positions and also involved in numerous clinical trials. He had more than 70 research publications including numerous national and international journals. He also guided postgraduate students and Guiding two Pharmacy doctoral students. His area of research interest includes Endocrinology, Adverse drug reaction management, Geriatric care etc.

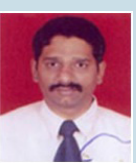

Dr. Nandakumar K: Working as an Associate Professor in the Department of Pharmacology Manipalcollege of pharmaceutical sciences. He guided more than $15 \mathrm{M}$.pharmstudents and guiding 3 doctoral students. He had more than 40 research publications being included in the national and international journals. He also got traveling grants for attending international conferences. His area of research interest includes CNS disorders (Anxiety, Epilepsy and Alzheimer's disease), Cardiometabolic disorders, analgesic, anti-inflammatory and Toxicological studies.

Dr. K. Sreedhara R Pai: Working as a Professor \& Head in the Department of Pharmacology Manipalcollege of pharmaceutical sciences. He guided more than $25 \mathrm{M}$. Pharm students and three doctoral students. Presently he is guiding four Ph D students. He is chairperson for various Manipal university extra -curricular activities. He got the best teacher award twice and he also got several grants from AICTE, DST \& Research promotion schemes. He had more than 50 Publications being included in the national and international journals. His area of research includes Diabetes, cancer, Toxicological \& Behavioral studies (Basic drug synthesizing stage to Clinical areas).

\section{REFERENCES}

1. Lim VH, Whitehurst $T$, Usoro $E, N$ g SM. Management of urinary tract infections in elderly patients: Strategies for improvement. BMJ Quallmprov Report. 2014;3:doi:10.1136/bmjquality.u203314.w1503.

2. Beveridge LA, Davey PG, Phillips G, McMurdo ME. Optimal management of urinary tract infections in older people. ClinInterv Aging. 2011;6(6):173-80.

3. Vasudevan R. Urinary tract infection: An overview of the infection and the associated risk factors. J Microbiol Exp. 2014;1(2):00008, doi:10.15406/ jmen.2014.01.00008.

4. Caljouw MA den Elzen WP Cools HJ, Gussekloo J. Predictive factors of urinary tract infections among the oldest old in the general population. A populationbased prospective follow-up study. BMC Med. 2011;9(1):57.

5. Cove-Smith A, Almond MK. Management of urinary tract infections in the elderly. Trends Urology, Gynecol. Sexual Health. 2007;12(4):31-4.

6. Mahesh E, Medha Y, Indumathi VA, Prithvi SK, Mohammed WK, Punith K. Community acquired UTI in elderly. BJMP 2011;4(1):a406.

7. Sood S, Gupta R. Antibiotic resistance pattern of community acquired uropathogens at a tertiary care hospital in Jaipur, Rajasthan. Indian J Community Med. 2012;37(1):39-44.

8. Shaifali I, Gupta U, Mahmood SE, Ahmed J. Antibiotic susceptibility patterns of urinary pathogens in female outpatients. N Am J Med Sci. 2012;4(4):163-9.

9. Beyene G, Tsegaye W. Bacterial uropathogens in urinary tract infection and antibiotic susceptibility pattern in Jimma University specialized hospital, southwest Ethiopia. Ethiop J Health Sci. 2011;21(2):141-6.

10. Mouton CP, Bazaldua OV, Pierce B, Espino DV. Common infections in older adults. Am Fam Physician. 2001;63(2):257-68.

11. Vijayanarayana K, Rau NR, Anantha NN, Bhavani Y, Girish T, Sreedharan N et al. An appraisal of sensitivity and resistance pattern of organisms isolated from hospital acquired pneumonia patients of a tertiary level teaching hospital: A prospective study. RJPBCS. 2014;5(4):384-98.

12. Chama S, Singh A, Cheruku AR, Shekar MC, Manu MK, Mohapatra AK et al. Antibiotic usage and sensitivity pattern in pulmonary medicine unit of a tertiary care teaching hospital in South India: A prospective study. Asian J Pharm Health Sci. 2014;4(3):1047-55

13. Dhodi DK, Jaiswar S, Bhagat SB, Gambre RS. A study to evaluate prescribing pattern of antibiotics among patients of urinary tract infection with preexisting renal disorders in a tertiary care hospital. Int J Basic Clin Pharmacol. 2014;3(4):687-91.
14. Faryabi R, Mathew J, Palaye M, Nair S, Shivshankar, Shetty PK, et al. Antibiotic utilization in patients with complicated urinary tract infection in the medicine wards of a South Indian tertiary care teaching hospital. RJPBCS. 2014:5(4):87-94

15. Mahesh E, Ramesh D, Indumathi VA, Punith K, Raj K, Anupama HA. Complicated urinary tract infection in a tertiary care center in South India. Al Ameen $J$ Med Sci. 2010;3(2):120-7.

16. Prakasam AKC, Dileesh KKG, Vijayan M. A cross sectional study on distribution of urinary tract infection and their antibiotic utilization pattern in Kerala. Int $J$ PharmTech Res. 2012,4(3):1310-6.

17. Prakash D, Saxena RS. Distribution and antimicrobial susceptibility pattern of bacterial pathogens causing urinary tract infection in urban community of Meerut City, India. ISRN Microbiology. 2013; 2013: Article ID 749629, doi: 10.1155/2013/749629.

18. Pargavi B, Mekala T, ThamaraiSelvi A, Moorthy K. Prevalence of urinary tract infection among diabetics patients in Vandavasi, Tamilnadu, India. Int J Biol Technol. 2011;2(2):42-5.

19. Marques LP, Flores JT, Barros JOO, Rodrigues GB, Mourão CM, Moreira RM Epidemiological and clinical aspects of urinary tract infection in communitydwelling elderly women. Braz J Infect Dis. 2012;16(5):436-41.

20. Fu AZ, Iglay K, Qiu Y, Engel S, Shankar R, Brodovicz K. Risk characterization for urinary tract infections in subjects with newly diagnosed type 2 diabetes. J Diabetes Complicat. 2014;28(6):805-10.

21. Ramanath KV, Shafiya SB. Prescription pattern of antibiotic usage for urinary tract infection treated in a rural tertiary care hospital. Indian J Pharmacy Practice. $2011 ; 4(2): 57-63$

22. Arslan H, Azap OK, Ergönül O, Timurkaynak F. Urinary tract infection study group. Risk factors for ciprofloxacin resistance among Escherichia coli strains isolated from community-acquired urinary tract infections in Turkey. J Antimicrob Chemother. 2005;56(5):914-8.

23. Peterson J, Kaul S, Khashab M, Fisher A, Kahn JB. Identification and pretherapy susceptibility of pathogens in patients with complicated urinary tract infection or acute pyelonephritis enrolled in a clinical study in the United States from November 2004 through April 2006. Clin Ther. 2007;29(10):2215-21.

24. Shalini, Joshi MC, Rashid MK, Joshi HS. Study of antibiotic sensitivity pattern in urinary tract infection at a tertiary hospital. NJIRM. 2011;2(3):43-6. 